\title{
Estudos sobre jornalismo digital no Brasil ${ }^{1}$
}

\author{
Claudia Irene Quadros ${ }^{2}$ \\ Universidade Tuiuti do Paraná \\ claudiaquadros@hotmail.com \\ Luciana Mielniczuk 3 \\ UFSM \\ luciana.mielniczuk@gmail.com \\ Suzana Barbosa 4 \\ UFBA \\ suzana.barbosa@gmail.com
}

\begin{abstract}
Resumo: Quem são os pioneiros na pesquisa sobre jornalismo digital no Brasil? Quantas teses e dissertações já foram defendidas sobre esta temática? Qual é o perfil das publicações? Essas são perguntas as quais se procura responder neste artigo, cujo objetivo é esboçar um levantamento preliminar sobre os estudos realizados na primeira década de desenvolvimento desta modalidade jornalística no país. Nossa hipótese é que existem quatro clusters de pesquisadores, localizados nas regiões Nordeste, Centro-Oeste, Sudeste e Sul.

Palavras-chave: Jornalismo digital; pesquisa; Brasil

Abstract: Who are the precursors in digital journalism research in Brazil? How many thesis and dissertations were already defended about this topic? What is the profile of these publications? These are some of the questions that we intend to answer in this article which proposes to outline a preliminary survey of the studies carried out during the first decade of development in this journalistic modality in the country. Our assumption is that there are four research clusters located in the Northeast, Center-west, Southeast and South regions of the country.
\end{abstract}

Key words: digital journalism ; research ; Brazil

1 O artigo foi aprovado para o IV Encontro da SBPJOR, em Porto Alegre, de 5 a 7 de novembro de 2006.

2 Professora do Programa de Mestrado em Comunicação e Linguagens da Universidade Tuiuti do Paraná.

3 Professora da Universidade Federal de Santa Maria.

4 Doutoranda na Universidade Federal da Bahia. Bolsista CNPq. 
Resumen: ¿Quién son los pioneros en la investigación sobre el periodismo digital en Brasil? ¿Cuántas tesis y tesinas ya fueron presentadas sobre el tema? ¿Cuál es el ámbito de las publicaciones? Esas son preguntas que intentamos contestar en este artículo, cuyo objetivo es plantear un levantamiento prelimininar respecto a los estudios hechos en la primera década del desarrollo de esta modalidad periodística en el país. Nuestra hipótesis es que existen cuatro clusters de investigadores, ubicados en las regiones nordeste, centro-oeste, sudeste y sur.

Palabras-clave: periodismo digital; investigación; Brasil

Résumé: Qui sont les pionniers de la recherche sur le journalisme digital ai Brésil? Combiens de thèses et de mémoires ont été soutenues sur ce sujet? Quelles sont les perspectives typiques de ces publications? Celles sont les questions qu' on essaie de répondre dans cet article, dont le but est une récolte préliminaire sur les études faits dans la première décénie du développement de cette production journalistique au pays. Notre hypothèse est qu' il y a quatre groupes de chercheurs qui se trouvent dans des régions du Nord-est, du Centre-Ouest, du Sud-Est et du Sud, respectivement.

Mots-clé: journalisme digital; recherche; Brésil.

\section{Introdução e método empregado}

Conhecer os pioneiros na pesquisa sobre jornalismo digital no Brasil e esboçar um levantamento - quantitativo - sobre os estudos realizados ao longo desses 10 anos são os objetivos deste artigo. Pretende-se verificar as instituições e regiões que mais têm se destacado, o número de teses e dissertações defendidas em torno da temática, além de mapear a atuação dos pesquisadores.

Trabalhamos com a hipótese de que há quatro clusters $^{5}$ de pesquisadores, distribuídos entre as regiões Nordeste, Centro-Oeste, Sudeste e Sul, nas quais os estudos nesta área de especialidade do jornalismo têm se desenvolvido, de modo constante e crescente. Esses pólos estão representados por seis pesquisadores que elegemos para iniciar nossos estudos sobre a produção científica em jornalismo digital.

Para se chegar aos seis nomes que são referidos aqui como os de produção mais consolidada e com maior atuação nas atividades de pesquisa e de orientação na pós-

\footnotetext{
${ }^{5}$ Ver: ARAÚJO, Denize. Estudos sobre Comunicação e Cibercultura no Brasil: conceitos, tendências e clusters, 2006 (artigo ainda não publicado pelo autor).
} 
graduação, empregou-se, inicialmente, a base de dados da Coordenação de Aperfeiçoamento de Pessoal de Nível Superior (CAPES) ${ }^{6}$ utilizando como palavras-chaves 'jornalismo on-line' e 'jornalismo digital' e, em seguida, foi feita a checagem a partir dos Currículos Lattes ${ }^{7}$. O cruzamento entre as informações obtidas nas duas bases de dados foi necessário, pois identificamos lacunas na produção dos pesquisadores, ora em uma das bases, ora em outra. Nos casos em que ainda pairavam dúvidas após a consulta às duas bases, os pesquisadores foram consultados por e-mail.

O texto está dividido em três partes: primeiro, uma breve apresentação dos pesquisadores; a seguir suas atuações na pós-graduação; por último, a produção intelectual dos pesquisadores.

\section{Os pesquisadores}

Os seis nomes selecionados para a realização deste levantamento - conforme os critérios metodológicos já explicitados - foram os seguintes: Claudia Irene Quadros (Univeridade Tuiuti do Paraná), Elias Machado Gonçalves (Universidade Federal de Santa Catarina) ${ }^{8}$, Elizabeth Saad (Universidade de São Paulo), Marcos Silva Palacios (Universidade Federal da Bahia), Sebastião Squirra (Universidade Metodista de São Paulo), Zélia Leal Adghirni (Universidade de Brasília).

No quadro abaixo é possível observar a titulação e o país de formação dos pesquisadores. Cabe informar que todos possuem formação na área de jornalismo digital.

Quadro 1 - Titulação dos pesquisadores.

\begin{tabular}{|l|l|l|l|c|}
\hline \multicolumn{1}{|c|}{ Pesquisador } & \multicolumn{1}{|c|}{ Titulação } & \multicolumn{1}{c|}{ Universidade de obtenção do título } & \multicolumn{1}{c|}{ País } & Ano \\
\hline Claudia Quadros & Doutor & Universidade de La Laguna & Espanha & 1999 \\
\hline Elias M. Gonçalves & Doutor & Universidade Autonoma de Barcelona & Espanha & 2000 \\
\hline Elizabeth Saad & Livre-docente & Universidade de São Paulo & Brasil & 2001 \\
\hline Marcos Palacios & Pós-doutor & Universidade de Aveiro & Portugal & 2003 \\
\hline Sebastião Squirra & Pós-doutor & Universidade da Carolina do Norte & Estados Unidos & 1996 \\
\hline Zélia L. Adghirni & Pós-doutor & Universidade de Rennes & França & 2000 \\
\hline
\end{tabular}

\footnotetext{
${ }^{6}$ Endereço: http://www.capes.gov.br/capes/portal/conteudo/10/Banco_Teses.htm.

${ }^{7}$ Endereço: http://buscatextual.cnpq.br/buscatextual/index.jsp

${ }^{8}$ Em junho de 2006, o pesquisador transferiu-se para a Universidade Federal de Santa Catarina, depois de atuar por mais de dez anos na Universidade Federal da Bahia.
} 
O quadro nos permite identificar que a formação desses pesquisadores se deu majoritariamente no exterior, especificamente na Europa (Espanha, Portugal e França), apenas um obteve o título no país e outro pesquisador nos Estados Unidos.

\section{Panorama da atuação na pós-graduação}

Cruzando as informações contidas nas bases de dados da CAPES e do CNPq, encontrou-se 52 trabalhos de mestrado e de doutorado, produzidos entre 1998 e 2005. Desse total, 28 trabalhos foram orientados pelos seis pesquisadores que estudamos, ou seja, pouco mais de 50\%. No Quadro 2 é possível visualizar a atuação dos referidos pesquisadores.

QUADRO 2 - Dissertações e teses orientadas pelos seis pesquisadores estudados.

\begin{tabular}{|c|c|c|c|c|}
\hline ORIENTADOR & MESTRADO & DOUTORADO & IES & TOTAL \\
\hline Claudia Quadros & $1-2004^{9}$ & --- & UTP & 01 \\
\hline Elias M. Conçalves & $4-2003$ & --- & UFBA & 04 \\
\hline Elizabeth Saad & $\begin{array}{l}5-2003 \\
1-2002 \\
1-2001\end{array}$ & $1-2004$ & USP & $08^{10}$ \\
\hline Marcos Palacios & $\begin{array}{l}1-2000 \\
2-2002 \\
2-2005\end{array}$ & $1-2003$ & UFBA & 06 \\
\hline Sebastião Squirra & $\begin{array}{l}1-2002 \\
1-2005 \\
\end{array}$ & $1-2003$ & $\mathrm{USP}^{11} / \mathrm{UMESP}$ & 03 \\
\hline Zélia L. Adghirni & $\begin{array}{l}1-2002 \\
3-2003 \\
1-2004 \\
1-2005 \\
\end{array}$ & -- & UNB & 06 \\
\hline \multicolumn{4}{|c|}{ TOTAL } & 28 \\
\hline
\end{tabular}

No Sudeste, a Universidade de São Paulo e a Universidade Metodista se destacam, tendo os professores Elizabeth Saad e Sebastião Squirra como os mais referenciados na

\footnotetext{
9 Para Claudia Quadros foi incluída apenas a dissertação Notícia sob medida - Jornalismo personalizado na internet por ser a que traz no título palavras que demonstram a especificidade do trabalho. ${ }_{10}$ Para Beth Saad, foram consideradas as dissertações que ela orientou e em cujos títulos havia referência à palavra "informação" e ou "jornalismo".

11 O professor Sebastião Squirra se aposentou da USP em 1998. Aqui, a instituição aparece indicada, pois foi lá que, em 2003, foi defendida a tese Mídia digital: o vigor das práticas jornalísticas em um novo espaço, de Walter Lima Júnior, orientada por ele.
} 
área, também pelo número de publicações, computando, ambos, um total de 11 dissertações e teses orientadas.

$\mathrm{Na}$ Bahia, dez trabalhos foram produzidos na Universidade Federal da Bahia, sendo que, até o momento apenas uma tese de doutorado foi defendida. $\mathrm{O}$ estado possui atuação destacada nesta área, pois, desde 1995 os professores Marcos Silva Palacios e Elias Machado Gonçalves iniciaram a investigação em jornalismo digital.

Zélia L. Adghirni destaca-se no Centro-Oeste, colocando a Universidade de Brasília como uma das instituições com grande contribuição para o desenvolvimento da pesquisa em jornalismo on-line. Ela começa a orientar dissertações que abordam o tema a partir de 2000, mantendo regularidade até o momento. No Sul, Claudia Quadros, talvez a primeira pesquisadora brasileira a defender uma tese sobre jornalismo on-line, em 1999, na Espanha, desponta. Ainda que com menor número de orientações até o momento, as suas pesquisas constantes na área - tanto no Brasil, como participando em redes de pesquisa internacionais -, além das publicações, lhe colocam à frente no cluster Sul.

Os 24 trabalhos restantes foram orientados desde 1998, de maneira esporádica, por 18 orientadores distribuídos entre oito diferentes universidades, conforme pode ser visualizado a seguir.

QUADRO 3 - Orientações realizadas por pesquisadores não estudados neste artigo.

\begin{tabular}{|c|c|c|c|c|}
\hline ORIENTADOR & MESTRADO & DOUTORADO & IES & TOTAL \\
\hline António Holfeltd & $1-2002$ & --- & PUCRS & 01 \\
\hline Elizabeth Moraes & $1-2003$ & $-\overline{--}$ & UMESP & 01 \\
\hline Erick Felinto de Oliveira & $1-2004$ & --- & UFRJ & 01 \\
\hline Francisco Menezes & $2-2001$ & $\overline{---}$ & PUCRS & 02 \\
\hline Gisela Ortriwano & $1-2000$ & --- & USP & 01 \\
\hline José Luiz Proença & --- & $1-2002$ & USP & 01 \\
\hline Julio César Machado Pinto & $\begin{array}{l}1-2000 \\
1-2001 \\
\end{array}$ & --- & UFMG & 02 \\
\hline Julio Plaza & $1-1999$ & --- & UNICAMP & 01 \\
\hline Juremir Machado da Silva & $1-2001$ & --- & PUCRS & 01 \\
\hline Luiz Fernando Santoro & $\begin{array}{l}1-2003 \\
2-2004 \\
\end{array}$ & --- & USP & 03 \\
\hline Marcia Benetti Machado & $1-2003$ & --- & UFRGS & 01 \\
\hline Marília Levacov & $\begin{array}{l}1-1998 \\
1-2004 \\
\end{array}$ & $\begin{array}{ll}-- \\
-1\end{array}$ & UFRGS & 02 \\
\hline Manuel Carlos Chaparro & $1-2002$ & --- & USP & 01 \\
\hline Mohammed Elhajji & $1-2003$ & --- & UFRJ & 02 \\
\hline
\end{tabular}


Revista da Associação Nacional dos

Programas de Pós-Graduação em Comunicação

\begin{tabular}{|l|c|c|c|c|}
\hline & $1-2004$ & & & \\
\hline Nelly de Camargo & --- & $1-2001$ & UNICAMP & 01 \\
\hline Sergio Capparelli & $1-1998$ & --- & UFRGS & 01 \\
\hline Raquel Paiva & $1-1999$ & --- & UFRJ & 01 \\
\hline Ronaldo Henn & $1-2003$ & --- & UNISINOS & 01 \\
\hline \multicolumn{3}{|c|}{ TOTAL } & $\mathbf{2 4}$ \\
\hline
\end{tabular}

Os dados da CAPES permitem inferir que as primeiras dissertações sobre jornalismo on-line foram produzidas na Universidade Federal do Rio Grande do Sul, com conclusão em 1998, sendo que, em seguida, aparecem os trabalhos orientados na Universidade Federal do Rio de Janeiro e na Unicamp. Já a primeira tese de doutorado foi defendida na Unicamp, em 2001. Vale notar que o pioneirismo nas defesas da pósgraduação não coube a nenhum dos seis pesquisadores que estudamos, como nos mostram os dois quadros anteriores.

Ao agregarmos os dados dos dois quadros, chega-se a um ranking por instituição no que se refere à quantidade de trabalhos produzidos sobre jornalismo digital. Desta maneira, temos o seguinte:

QUADRO 4 - Números de trabalhos e instituições em que foram defendidos.

\begin{tabular}{|c|c|}
\hline IES & $\begin{array}{c}\text { Número de } \\
\text { trabalhos }\end{array}$ \\
\hline USP & 17 \\
\hline UFBA & 10 \\
\hline UNB & 06 \\
\hline UFRGS & 04 \\
\hline PUCRS & 04 \\
\hline UFRJ & 04 \\
\hline UFMG & 02 \\
\hline UNICAMP & 02 \\
\hline UNISINOS & 01 \\
\hline UMESP & 01 \\
\hline UTP & 01 \\
\hline TOTAL & $\mathbf{5 2}$ \\
\hline
\end{tabular}

Para avaliar $\mathrm{o}$ andamento $\mathrm{da}$ pesquisa nas referidas instituições $\mathrm{e} o$ desenvolvimento da investigação nos clusters citados, realizamos, uma vez mais, a checagem, cruzamento e análise das informações entre os dados da CAPES e do CNPq. 
QUADRO 5 - Orientações em andamento.

\begin{tabular}{|l|c|c|c|c|c|}
\hline \multicolumn{1}{|c|}{ Orientador } & Mestrado & Doutorado & IES & Região & Total \\
\hline Claudia Quadros & 03 & --- & UTP & Sul & 03 \\
\hline Elias M. Gonçalves & --- & 01 & UFBA & Nordeste & 01 \\
\hline Elizabeth Saad & 01 & 03 & USP & Sudeste & 04 \\
\hline Juremir Machado da Silva & --- & 01 & PUCRS & Sul & 01 \\
\hline Marcos Palacios & 02 & 03 & UFBA & Nordeste & 05 \\
\hline Sebastião Squirra & --- & --- & UMESP & Sudeste & --- \\
\hline Zélia Leal Adghirni & --- & 01 & UNB & Centro-oeste & 01 \\
\hline
\end{tabular}

No total são 15 orientações em andamento, sendo que seis delas estão na UFBA, quatro na USP, quatro no sul (três na UTP e uma na PUCRS) e uma na UnB.

A partir do quadro anterior identifica-se a presença de mais teses em elaboração do que dissertações, fato que, por um lado, demonstra o amadurecimento da pesquisa na área, mas, por outro, desperta o questionamento sobre uma possível diminuição do interesse sobre o assunto entre os mestrandos.

Também é possível perceber a regularidade da pesquisa, que, de fato, se apresenta consolidada nos clusters Bahia, com Marcos Palacios (com cinco orientações) e Elias Machado Gonçalves, reafirmando a liderança na região Nordeste. No Sudeste, Elizabeth Saad fica em evidência, enquanto Sebastião Squirra aparece neste momento sem orientações em jornalismo digital; Centro-Oeste, com Zélia L. Adghirni, e Sul, com Claudia Quadros. Também no Sul, Juremir Machado Silva surge como orientador de um segundo trabalho em jornalismo digital.

\section{Levantamento de publicações}

Nesta parte do texto discorremos sobre as publicações disponíveis, em junho de 2005, no Currículo Lattes dos pesquisadores estudados12. É importante destacar que um mesmo artigo publicado em diferentes idiomas foi contabilizado como duas produções, não pelo trabalho de tradução, mas, sobretudo, por sua repercussão. Artigos publicados em periódicos especializados e, depois, incluídos em capítulos de livro também foram considerados como produções distintas.

\footnotetext{
12 Analisamos os currículos disponibilizados pelos pesquisadores, sem entrar no mérito sobre o preenchimento dos mesmos. Apenas registramos os itens por eles apresentados.
} 
O quadro a seguir indica, quantitativamente, a produção de artigos, livros (organizados ou escritos pelo pesquisador) e capítulos de livros.

QUADRO 6 - Dados quantitativos sobre a produção dos pesquisadores estudados ${ }^{13}$.

\begin{tabular}{|l|l|l|l|l|}
\hline Pesquisadores & $\begin{array}{l}\text { Artigos } \\
\text { científicos }\end{array}$ & Livros & $\begin{array}{l}\text { Capítulos de } \\
\text { livros }\end{array}$ & TOTAL \\
\hline Claudia Quadros & 8 & 1 & 1 & 10 \\
\hline Elias M. Gonçalves & 12 & 4 & 4 & 20 \\
\hline Elizabeth Saad & 6 & 2 & 2 & 10 \\
\hline Marcos Palacios & 8 & 3 & 7 & 18 \\
\hline Sebastião Squirra & 6 & 1 & --- & 7 \\
\hline Zélia L. Adghirni & 3 & --- & 3 & 6 \\
\hline
\end{tabular}

$\mathrm{Na}$ sequência, apresentamos comentários gerais sobre a produção de cada pesquisador.

\subsection{Claudia Quadros}

Sua tese de doutorado, entre as pioneiras sobre o assunto, defendida na Espanha, foi publicada em forma de livro no ano de 2005 pela editora da Universidade de La Laguna. Seus demais trabalhos foram publicados na Espanha (Ámbitos, Revista Latina de Comunicación e Quaderns Digitals) e no Brasil (E-compós, 404 notfound e Em Questão).

Nos artigos publicados em periódicos especializados, Quadros reflete sobre as reconfigurações dos meios de comunicação, a ética, os novos formatos e práticas dos jornais digitais, as possibilidades proporcionadas pelo avanço tecnológico e os sistemas emergentes. O conjunto de sua obra demonstra a intenção de contribuir para um registro histórico sobre o estado da arte do jornalismo digital.

QUADRO 7 - Resumo da produção autoral de Claudia Quadros.

\begin{tabular}{|l|l|l|l|l|}
\hline \multicolumn{1}{|c|}{ Título } & Ano & \multicolumn{1}{c|}{ Tipo } & Autoria & \multicolumn{1}{c|}{ País } \\
\hline $\begin{array}{l}\text { Los periodistas y diarios electrónicos:las exigencias } \\
\text { profesionales en la Red.. }\end{array}$ & 2005 & livro & individual & Espanha \\
\hline
\end{tabular}

${ }^{13}$ Consideramos somente a produção publicada, registrada como artigo científico, livro (escritos na íntegra ou organizados) e capítulo de livro. Neste artigo não haveria espaço para considerar os trabalhos apresentados em eventos científicos. 
Revista da Associação Nacional dos Programas de Pós-Graduação em Comunicação

\begin{tabular}{|l|l|l|l|l|}
\hline Uma Breve Visão Histórica do Jornalismo On-line. & 2002 & capítulo & individual & Brasil \\
\hline Blogs e as transformações no Jornalismo. & 2005 & artigo & co-autoria & Brasil \\
\hline Dez Anos Depois do Boom dos Diários Digitais. & 2005 & artigo & individual & Brasil \\
\hline Base de dados: a memória extensiva do jornalismo. & 2005 & artigo & individual & Brasil \\
\hline $\begin{array}{l}\text { A participação do público no webjornalismo. } \\
\text { Clinton-Lewinsky: l'escàndol que va començar en la } \\
\text { Xarxa. }\end{array}$ & 2000 & artigo & individual & Brasil \\
\hline $\begin{array}{l}\text { Una discusión sobre la ética en los periódicos } \\
\text { electrónicos. }\end{array}$ & 2000 & artigo & individual & Espanha \\
\hline $\begin{array}{l}\text { Clinton-Lewindual } \\
\text { Red }\end{array}$ & Espanha \\
\hline Ser digital: um novo desafio para os jornalistas . & 1999 & artigo & individual & Brasil \\
\hline
\end{tabular}

\subsection{Elias Machado Gonçalves}

Antes de inciar o doutorado, o pesquisador já atuava na área, em meados dos 1990, em parceria com Marcos Palacios, também professor na UFBA. Atual presidente da Sociedade Brasileira de Pesquisadores em Jornalismo (SBPJor), Elias Machado Gonçalves destaca-se pelas iniciativas adotadas no intuito de desenvolver a pesquisa no campo do jornalismo e intensificar o intercâmbio internacional, e consequentemente, no seu foco de atuação, o jornalismo digital. Como reconhecimento da comunidade científica, neste ano de 2006, recebe o Prêmio Luiz Beltrão de Ciências da Comunicação ${ }^{14}$, na categoria liderança emergente.

Dos 12 artigos publicados sobre jornalismo digital, cinco foram elaborados com orientandos e/ou outros pesquisadores. Os trabalhos foram publicados na Espanha (Zer Revista de Comunicación e Scripta Nueva), no México (Raźón y Palabra) e no Brasil (Pauta Geral, Textos de Cultura e Comunicaşão e Comunicação e Sociedade). A maior parte de sua produção, inclusive os trabalhos apresentados em congressos, está disponível na Internet, no site do Grupo de Pesquisa em Jornalismo Online ${ }^{15}$ ou na Biblioteca On-line de Ciências da Informação ${ }^{16}$.

Nos trabalhos desenvolvidos por Machado, encontramos preocupações relacionadas à sistematização das investigações em jornalismo digital, à falta da valorização da pesquisa aplicada no Brasil, aos efeitos provocados pela tecnologia nos meios de

\footnotetext{
${ }^{14}$ Esse prêmio é outorgado anualmente pela Sociedade Brasileira de Estudos Interdisciplinares da Comunicação (Intercom) a pesquisadores e instituições científicas.

${ }^{15}$ Endereço: http://www.facom.ufba.br/jol

${ }^{16}$ Endereço: http://www.bocc.ubi.pt
} 
comunicação, aos novos sistemas de produção e distribuição da notícia e às novas formas de narrativas no ciberespaço. A repercussão de seus estudos pode ser observada no resultado do Google Scholar, sistema de busca exclusivo de trabalhos científicos: são centenas os investigadores que citam as pesquisas desenvolvidas pelo autor.

QUADRO 8 - Resumo da produção autoral de Elias Machado Gonçalves.

\begin{tabular}{|c|c|c|c|c|}
\hline Título & Ano & Tipo & Autoria & País \\
\hline O ciberespaço como fonte para os jornalistas. & 2003 & livro & individual & Brasil \\
\hline Modelos de jornalismo digital. & 2003 & livro (org.) & co-autoria & Brasil \\
\hline $\begin{array}{l}\text { La Estructura de la noticia en las redes digitales } \\
\text { [Microforma] : un estudio de las consecuencias de } \\
\text { las metamorfosis tecnológicas en el periodismo. }\end{array}$ & 2001 & $\begin{array}{l}\text { livro } \\
\text { (microforma) }\end{array}$ & individual & Espanha \\
\hline $\begin{array}{l}\text { Manual de jornalismo na Internet - noções } \\
\text { básicas, conceitos e um guia sobre as principais } \\
\text { publicações jornalisticas digitais no Brasil e no } \\
\text { Exterior. }\end{array}$ & 1997 & livro & co-autoria & Brasil \\
\hline $\begin{array}{l}\text { Comunicação e Informação - O Global e o Local } \\
\text { em Austin e Salvador. }\end{array}$ & 2005 & capítulo & co-autoria & Brasil \\
\hline $\begin{array}{l}\text { Modelos de produção de conteúdos no jornalismo } \\
\text { digital baiano. }\end{array}$ & 2004 & capítulo & co-autoria & Portugal \\
\hline Modelos de produção no jornalismo digital baiano & 2003 & capítulo & co-autoria & Brasil \\
\hline $\begin{array}{l}\text { Changing concepts of time } 50 \text { anos depois - a } \\
\text { contribuição de Harold Innis para o estudo do } \\
\text { jornalismo digital }\end{array}$ & 2003 & capítulo & individual & Brasil \\
\hline $\begin{array}{l}\text { La experiencia de la enseñanza del periodismo } \\
\text { digital en la FACOM/UFBA 1995/2005. }\end{array}$ & 2006 & artigo & co-autoria & Espanha \\
\hline $\begin{array}{l}\text { Um jornal multi-usuário, descentralizado e } \\
\text { multimídia. O caso da Plataforma Panopticon. }\end{array}$ & 2005 & artigo & co-autoria & Brasil \\
\hline $\begin{array}{l}\text { Um Jornal Laboratório multimídia, multi-usuário } \\
e \text { descentralizado. O caso da Plataforma } \\
\text { Panopticon. }\end{array}$ & 2006 & artigo & co-autoria & México \\
\hline Gêneros narrativos no jornalismo digital baiano. & 2003 & artigo & co-autoria & Brasil \\
\hline $\begin{array}{l}\text { A Intranet como modelo de gestão no jornalismo } \\
\text { digital. }\end{array}$ & 2004 & artigo & individual & Brasil \\
\hline $\begin{array}{l}\text { O jornal como epicentro das redes de circulação } \\
\text { de notícias. }\end{array}$ & 2002 & artigo & individual & Brasil \\
\hline Os enredados no ciberespaço. & 2002 & artigo & individual & Brasil \\
\hline La circulación de la noticia en las redes digitales. & 2000 & artigo & individual & Espanha \\
\hline O novo conceito de edição no jornalismo digital. & 2000 & artigo & individual & Portugal \\
\hline O jornalismo digital no mercado global. & 1998 & artigo & individual & Brasil \\
\hline $\begin{array}{l}\text { Três modelos de jornalismo personalizado na } \\
\text { Internet - Fishwrap, Pointcast e CRAYON. }\end{array}$ & 1996 & artigo & co-autoria & Brasil \\
\hline $\begin{array}{l}\text { A produção verticalizada da notícia no jornalismo } \\
\text { digital. }\end{array}$ & 1996 & artigo & individual & Brasil \\
\hline
\end{tabular}

\subsection{Elizabeth Saad}


Elizabeth Nicolau Saad Côrrea é referência quando se trata de jornalismo e negócios na rede. Já no doutorado em Ciências da Comunicação, defendido em 1994, ela uniu tecnologia, jornalismo e mercado para fazer uma análise da Agência Estado. Na livredocência, obtida em 2001, apresentou a pesquisa As estratégias da desconstrução. Sobre o uso de estratégias diferenciadas por empresas informativas na Internet. Parte do resultado desse trabalho pode ser conferido no livro Estratégias para a mídia digital., lançado em 2003. Utilizando exemplos internacionais e nacionais, como The New York Times, Financial Times, Mercury Center, Uol, Estadão, Grupo Abril e Organizações Globo, a autora faz uma análise de modelos e processos estratégicos para a informação digital. A proposta do livro é refletir sobre ações de empresas de comunicação na era digital. De maneira geral, Saad reforça a "impossibilidade de receitas prontas quando falamos de operações de Internet" (2003, p. 26) e assume que toda empresa do século XXI deve integrar a Internet como uma atividade normal.

Os artigos científicos sobre jornalismo digital somam sete, sendo que seis foram publicados em revistas brasileiras, como Revista da USP, Pauta Geral, Novos Olhares e Brazilian Journalism Research e um na revista mexicana Razón y Palabra.

QUADRO 9 - Resumo da produção autoral de Elizabeth Saad.

\begin{tabular}{|l|l|l|l|l|}
\hline \multicolumn{1}{|c|}{ Título } & Ano & \multicolumn{1}{|c|}{ Tipo } & \multicolumn{1}{|c|}{ Autoria } & \multicolumn{1}{|c|}{ País } \\
\hline $\begin{array}{l}\text { Estratégias para a midia digital, internet, informação } \\
\text { e comunicação. }\end{array}$ & 2003 & livro & individual & Brasil \\
\hline $\begin{array}{l}\text { Em Alta - O primeiro guia on-line de jornalismo } \\
\text { econômico. }\end{array}$ & 1998 & livro & co-autoria & Brasil \\
\hline $\begin{array}{l}\text { Linguagens da informação digital: reflexões } \\
\text { conceituais e uma proposta de sistematização. }\end{array}$ & 2005 & capítulo & individual & Brasil \\
\hline A era do ciberjornalista. & 2000 & capítulo & individual & Brasil \\
\hline $\begin{array}{l}\text { O jornalismo contemporâneo no Brasil: as midias } \\
\text { digitais como elo entre a crise e a busca de uma nova } \\
\text { identidade. }\end{array}$ & 2005 & artigo & individual & México \\
\hline $\begin{array}{l}\text { Contemporary journalism in Brazil: } \text { digital media as } \\
\text { a link between the crisis and the search of a new } \\
\text { identity. }\end{array}$ & 2005 & artigo & individual & Brasil \\
\hline O direito à informaçáa e o dever de informar. & 2003 & artigo & individual & Brasil \\
\hline $\begin{array}{l}\text { Arquitetura estratégica no horizonte da terra cógnita } \\
\text { da informação digital. }\end{array}$ & 2001 & artigo & individual & Brasil \\
\hline $\begin{array}{l}\text { O jornalista brasileiro na sociedade da informação: } \\
\text { repórter da realidade, arquiteto da virtualidade. }\end{array}$ & 1999 & artigo & individual & Brasil \\
\hline $\begin{array}{l}\text { Jornalismo e competitividade: o caso da Agência } \\
\text { Estado. }\end{array}$ & 1997 & artigo & individual & Brasil \\
\hline
\end{tabular}




\subsection{Marcos Palacios}

O mais experiente pesquisador entre os selecionados, Marcos Silva Palacios dá início à investigação sobre jornalismo digital em 1995. O conjunto de sua produção acerca deste tema reúne reflexões sobre ensino, metodologia, narrativas e tecnologia.

Em 1996, ele e Elias Machado Gonçalves, então professor da Universidade Federal da Bahia, disponibilizam na rede o Manual de Jornalismo Online, com parte do material elaborado para a Oficina de Jornalismo On-line dirigida aos alunos da graduação, no ano anterior. Aquele era um período em que começava a proliferação de jornais digitais e a discussão, na academia e no mercado, sobre as reais possibilidades da Internet para o desenvolvimento do jornalismo ainda era tímida. A parceria com Elias Machado Gonçalves rende outros estudos e publicações. Em 2003, organizam o livro Modelos de Jornalismo Digital. Os artigos são resultados de pesquisas desenvolvidas pelos integrantes do Grupo de Pesquisa em Jornalismo Online (GJOL) ${ }^{17}$.

Dos oito artigos publicados, três estão em revistas internacionais: Razón y Palabra (México), Zer Revista de Comunicación (Espanha) e Comunicarte (Portugal), e cinco em nacionais: Pauta Geral, Textos de Cultura e Comunicaşão, Jornalismo Cultural e E-Compos. Os artigos, em sua maioria, são produzidos com membros do GJOL e apontam resultados de estudos realizados pelo grupo.

QUADRO 10 - Resumo da produção autoral de Marcos Palacios.

\begin{tabular}{|l|l|l|l|l|}
\hline \multicolumn{1}{|c|}{ Título } & \multicolumn{1}{|c|}{ Ano } & \multicolumn{1}{c|}{ Tipo } & \multicolumn{1}{c|}{ Autoria } & \multicolumn{1}{c|}{ País } \\
\hline Manual de Jornalismo Online & 1996 & livro & co-autoria & Brasil \\
\hline Manual de Jornalismo na Internet. & 1997 & livro & co-autoria & Brasil \\
\hline $\begin{array}{l}\text { Modelos de jornalismo digital. } \\
\text { Considerações para um estudo sobre o formato da } \\
\text { notícia na Web: } \text { o link como elemento paratextual. }\end{array}$ & 2003 & livro (org.) & co-autoria & Brasil \\
\hline $\begin{array}{l}\text { Jornalismo Online, Informação e Memória: } \\
\text { apontamentos para debate. }\end{array}$ & 2003 & capítulo & co-autoria & Brasil \\
\hline Três modelos de Jornalismo Digital. & individual & Portugal \\
\hline Três modelos de Jornalismo Digital. & 2003 & capítulo & co-autoria & Brasil \\
\hline $\begin{array}{l}\text { Ruptura, continuidade e potencialização no } \\
\text { jornalismo on-line: o lugar da memória. }\end{array}$ & 2003 & capítulo & individual & Brasil \\
\hline $\begin{array}{l}\text { Jornalismo em ambiente plural? Notas para } \\
\text { discussão da Internet enquanto suporte para a }\end{array}$ & 2004 & capítulo & individual & Brasil \\
\hline
\end{tabular}

\footnotetext{
${ }_{17}$ Grupo de pesquisa coordenado por Palacios e Machado na Universidade Federal da Bahia e
} registrado no Conselho Nacional de Desenvolvimento Científico e Tecnológico em 2001. 


\begin{tabular}{|l|l|l|l|l|}
\hline prática jornalística. & & & & \\
\hline $\begin{array}{l}\text { O Uso da Fotografia no Jornalismo On-Line em } \\
\text { Salvador e Austin: primeiros elementos de uma } \\
\text { análise comparativa. }\end{array}$ & 2004 & capítulo & co-autoria & Brasil \\
\hline O Jornalismo Personalizado Na Internet. & 1996 & artigo & co-autoria & Brasil \\
\hline $\begin{array}{l}\text { Considerações para um estudo sobre o formato da } \\
\text { notícia na Web: o link como elemento paratextual. }\end{array}$ & 2002 & artigo & co-autoria & Brasil \\
\hline $\begin{array}{l}\text { Um Mapeamento de características e tendências no } \\
\text { jornalismo online brasileiro e português. }\end{array}$ & 2002 & artigo & co-autoria & Portugal \\
\hline $\begin{array}{l}\text { Fazendo Jornalismo em Redes Hibridas: Notas para } \\
\text { discussão da Internet enquanto suporte mediático. }\end{array}$ & 2003 & artigo & individual & Brasil \\
\hline $\begin{array}{l}\text { Um jornal multi-usuário, descentralizado e } \\
\text { multimidia. O caso da Plataforma Panopticon. }\end{array}$ & 2005 & artigo & co-autoria & Brasil \\
\hline $\begin{array}{l}\text { La experiencia de la enseñanza del periodismo } \\
\text { digital en la FACOM/UFBA 1995/2005. Zer Revista } \\
\text { de Comunicación, Bilbao, v. 20, n. } 1,2005 .\end{array}$ & artigo & co-autoria & Espanha \\
\hline $\begin{array}{l}\text { Natura non facit saltum: Promessas, alcances e } \\
\text { limites no desenvolvimento do jornalismo on-line e } \\
\text { da hiperficção. }\end{array}$ & 2005 & artigo & individual & Brasil \\
\hline $\begin{array}{l}\text { Um Jornal Laboratório multimídia, multi-usuário e } \\
\text { descentralizado. O caso da Plataforma Panopticon. }\end{array}$ & 2006 & artigo & co-autoria & México \\
\hline
\end{tabular}

\subsection{Sebastião Squirra}

Sebastião Squirra, o autor do primeiro livro sobre jornalismo nas redes digitais editado no Brasil, em 1998, cujo título é Jorn@lismo Online. A obra resulta da pesquisa de pós-doutorado, na Universidade da Carolina do Norte, Estados Unidos. A maior parte da produção de Squirra versa sobre televisão. Sobre jornalismo digital, além do livro, há seis artigos, sendo que, cinco publicados no Brasil e um na Bolívia. O mais antigo é de 1995 e descreve a importância da internet para a comunicação. Outros quatro artigos datam de 1998, mesmo ano em que o livro foi publicado, e apresentam tendências do jornalismo no ciberespaço. No artigo mais recente, em 2002, Squirra une o telejornalismo e a Internet.

QUADRO 11 - Resumo da produção autoral de Sebastião Squirra.

\begin{tabular}{|l|c|l|l|l|}
\hline \multicolumn{1}{|c|}{ Título } & Ano & \multicolumn{1}{c|}{ Tipo } & \multicolumn{1}{c|}{ Autoria } & \multicolumn{1}{c|}{ País } \\
\hline Jorn@lismo Online & 1998 & livro & individual & Brasil \\
\hline O telejornalismo na Internet. & 2002 & artigo & individual & Brasil \\
\hline Periodismo en el ciberespacio. & 1998 & artigo & individual & Bolívia \\
\hline Ojornalismo do futuro. & 1998 & artigo & individual & Brasil \\
\hline Jornalismo no ciberespaço. & 1998 & artigo & individual & Brasil \\
\hline Viagem ao mundo ciberespacial. & 1998 & artigo & individual & Brasil \\
\hline Internet. & 1995 & artigo & individual & Brasil \\
\hline
\end{tabular}




\subsection{Zélia Leal Adghirni}

O papel do jornalista nas rotinas produtivas das empresas de comunicação é o principal foco das investigações desenvolvidas por Zelia Leal Adghirni. Seus textos versam, de modo geral, sobre as reconfigurações dos meios e da rotina de seus profissionais provocadas pelos efeitos da tecnologia e da evolução sociocultural, política e econômica. Ao analisar as redações on-line de Brasília em contraste com outras realidades nacionais e internacionais, ela pensa o local para agir de forma global.

Em Jornalismo online: em busca do tempo real, Adghirni analisa a obsessão de velocidade nos meios de comunicação, enfatizando mudanças nas rotinas produtivas de redações digitais e, consequentemente, no produto final, provocadas por esse novo tempo acelerado. A pesquisadora questiona se o jornalista (analista do dia) não é na verdade um instantaneísta (analista do instante) da notícia.

QUADRO 12 - Resumo da produção autoral de Zélia Leal Adghirni.

\begin{tabular}{|l|l|l|l|l|}
\hline \multicolumn{1}{|c|}{ Título } & \multicolumn{1}{c|}{ Ano } & \multicolumn{1}{c|}{ Tipo } & \multicolumn{1}{c|}{ Autoria } & \multicolumn{1}{c|}{ País } \\
\hline Jornalismo online: em busca do tempo real. & 2002 & capítulo & individual & Brasil \\
\hline La presse en ligne au Bresil. & 2002 & capítulo & individual & França \\
\hline $\begin{array}{l}\text { Jornalismo online e identidade profissional do } \\
\text { jornalista. }\end{array}$ & 2002 & capítulo & individual & Brasil \\
\hline La presse en ligne au Brésil: temps réel et realité & 2002 & artigo & individual & França \\
\hline $\begin{array}{l}\text { Informação online: jornalista ou produtor de } \\
\text { conteúdos? }\end{array}$ & 2002 & artigo & co-autoria & Brasil \\
\hline $\begin{array}{l}\text { Jornalismo online e identidade profissional do } \\
\text { jornalista. }\end{array}$ & 2001 & artigo & individual & Brasil \\
\hline
\end{tabular}

\section{A pesquisa e a metodologia sobre Jornalismo Digital}

Atualmente, quatro dos investigadores selecionados desenvolvem projetos específicos de pesquisa sobre jornalismo digital. Sebastião Squirra apresenta uma investigação mais abrangente sobre comunicação e tecnologias digitais, já Zélia L. Adghirni estuda processos de produção da notícia no limite das fronteiras híbridas dos gêneros redacionais (informação/opinião) e profissionais junto às esferas midiáticas governamentais. 
Quadro 13 - Título das pesquisas atuais dos investigadores selecionados.

\begin{tabular}{|c|c|c|c|}
\hline Pesquisador & Projeto & Ano & Financiamento \\
\hline Claudia Quadros & $\begin{array}{l}\text { Arquitetura Web: a estrutura da notícia no } \\
\text { jornal }\end{array}$ & $2004-$ atual & UTP \\
\hline \multirow[t]{3}{*}{ Elias M. Gonçalves } & $\begin{array}{l}\text { O jornalismo digital em publicações regionais } \\
\text { no Brasil e nos Estados Unidos - Um estudo } \\
\text { comparativo dos sistemas de produção da } \\
\text { notícia em Austin e Salvador }\end{array}$ & $2002-$ atual & CAPES \\
\hline & $\begin{array}{l}\text { Rede Latino-americana para pesquisa de } \\
\text { metodologias e softwares para o ensino de } \\
\text { jornalismo nas redes digitais de alta } \\
\text { velocidade }\end{array}$ & 2003 - atual & CNPq/Fapesb \\
\hline & $\begin{array}{l}\text { Projeto Alpha: Rede ICOD para estudos dos } \\
\text { componentes digitais no ensino da } \\
\text { Comunicação }\end{array}$ & 2004 - atual & $\begin{array}{l}\text { Comunidade } \\
\text { Européia }\end{array}$ \\
\hline Elizabeth Saad & Linguagens Digitais & 2002 - atual & USP \\
\hline \multirow[t]{3}{*}{ Marcos Palacios } & $\begin{array}{l}\text { Jornalismo em Redes Digitais: } \\
\text { problematizando a Internet enquanto suporte } \\
\text { para a prática do Jornalismo }\end{array}$ & 2003 - atual & $\mathrm{CNPq}$ \\
\hline & $\begin{array}{l}\text { Rede Latino-americana para pesquisa de } \\
\text { metodologias e softwares para o ensino de } \\
\text { jornalismo nas redes digitais de alta } \\
\text { velocidade }\end{array}$ & 2003 - atual & $\mathrm{CNPq} / \mathrm{Fapesb}$ \\
\hline & $\begin{array}{l}\text { Projeto Alfa: Rede ICOD para estudos dos } \\
\text { componentes digitais no ensino da } \\
\text { Comunicação }\end{array}$ & 2004 - atual & $\begin{array}{l}\text { Comunidade } \\
\text { Européia }\end{array}$ \\
\hline Sebastião Squirra & Comunicação e Tecnologias Digitais & 2004 - atual & $\mathrm{CNPq}$ \\
\hline Zélia L. Adghirni & $\begin{array}{l}\text { Hibridição dos gêneros midiáticos e dos } \\
\text { gêneros profissionais }\end{array}$ & 2003 - atual & $\mathrm{CNPq}$ \\
\hline
\end{tabular}

Ao longo de dez anos de pesquisa, os investigadores selecionados se utilizaram de diversas metodologias para a realização de seus estudos, que vão desde entrevistas em profundidade, levantamentos bibliográficos extensivos, observação sistemática, classificação etc. De modo geral, reuniram instrumentos quantitativos e qualitativos adaptados para o estudo do jornalismo digital. A união dos dois métodos permitiram encontrar soluções ou respostas mais seguras sobre o problema em foco. Há necessidade, no entanto, de um estudo aprofundado das metodologias desenvolvidas ao longo da década, também com o intuito de criar novas metodologias para a compreensão da evolução do jornalismo digital. 


\section{Considerações finais}

Um levantamento desta natureza, com enfoque quantitativo, não se configura como um trabalho pleno. Trata-se de uma etapa inicial: a sistematização acerca dos estudos na área de jornalismo digital realizados no Brasil na primeira década de existência do objeto de pesquisa. Mesmo sendo apenas um levantamento preliminar pudemos conhecer aspectos bastante significativos deste cenário.

Temos três pós-doutores, um livre-docente e dois doutores. Constatamos que a formação dos nossos pesquisadores pioneiros ocorreu majoritariamente no exterior, especificamente na Europa (Espanha, França e Portugal); apenas um pesquisador obteve seu título nos Estados Unidos e outro no Brasil. Isso se reflete no número de publicações editadas no exterior: Espanha (oito), Portugal (três), México (três), França (duas) e Bolívia (uma). Nenhum pesquisador indica no Currículo Lattes publicação editada nos Estados Unidos.

Outra observação: no cluster Nordeste (Bahia), os coordenadores do Grupo de Pesquisa em Jornalismo On-line possuem maior incidência de produção de textos em coautoria. Esse dado, provavelmente, reflete o desenvolvimento do trabalho em equipe.

Entre as nossas descobertas, verificamos que, dos 52 trabalhos (dissertações e teses), 28 foram orientados pelos seis pesquisadores destacados, ou seja, 53,8\% do montante total. Os restantes 24 trabalhos ficaram a cargo de 18 orientadores. Detectamos ainda que, dos trabalhos em andamento, há seis dissertações e nove teses, dado que aponta o amadurecimento das pesquisas realizadas na área. Porém, esses trabalhos não estão divididos de maneira equilibrada entre os pesquisadores - 12 das 15 orientações em andamento estão sob a responsabilidade de três pesquisadores: Marcos Palacios (dois mestrados e três doutorados), Elizabeth Saad (um mestrado e três doutorados) e Claudia Quadros (três mestrados). Os demais pesquisadores orientam apenas um trabalho, sendo que Sebastião Squirra não possui orientandos na área neste momento.

A partir do panorama esboçado, pretendemos continuar estudando os caminhos da pesquisa em jornalismo digital no Brasil, não só de maneira quantitativa, mas com uma 
abordagem qualitativa que nos permita apresentar e analisar as investigações desenvolvidas pelos pesquisadores brasileiros.

\section{Referências bibliográficas da produção dos pesquisadores estudados}

\subsection{Publicações de Claudia Quadros}

\section{Livro}

QUADROS, C. I. . Los periodistas y diarios electrónicos:las exigencias profesionales en la Red.. 1. ed. La Laguna: Editora: Latina de Comunicación - Universidad de La Laguna, 2005.

\section{Capítulo de Livro}

QUADROS, C. I. . Uma Breve Visão Histórica do Jornalismo On-line. In: Antonio Hohlfeldt; Marialva Barbosa. (Org.). Jornalismo no Século XXI: a Cidadania. 1 ed. Porto Alegre: Mercado Aberto, 2002, v. , p. 239-259.

\section{Artigos}

QUADROS, C. I. ; VIEIRA, Josiany Fiedler ; ROSA, A. P. . Blogs e as transformações no Jornalismo. e-compos, Salvador, v. 3, n. 1, 2005.

QUADROS, C. I. . Dez Anos Depois do Boom dos Diários Digitais. 404nOtFound, Salvador, v. I, n. 50, 2005.

QUADROS, C. I. . Base de dados: a memória extensiva do jornalismo. Em Questão, Rio Grande do Sul, v. 11, n. 2, 2005.

QUADROS, C. I. . A participação do público no webjornalismo. E-Compós: Revista da Associação Nacional de Programas de Pós-graduação em Comunicação, v. 4, n. dez., p. 1-17, 2005.

QUADROS, C. I. . Clinton-Lewinsky: l'escàndol que va començar en la Xarxa. Quaderns Digitals, Valencia, v. 20, 2000.

QUADROS, C. I. . Una discusión sobre la ética en los periódicos electrónicos. Revista Ámbitos, Sevilha, p. 145-151, 2000.

QUADROS, C. I. Clinton-Lewinsky: el escándalo que comenzó en la Red, Revista Latina de Comunicación Social, La Laguna, Espanha, 1999.

QUADROS, C. I. . Ser digital: um novo desafio para os jornalistas . Jornal Brasileiro das Ciências da Comunicação, São Paulo, 1999. 


\subsection{Publicações de Elias Machado Gonçalves}

\section{Livros}

GONÇALVES, E. M. . O ciberespaço como fonte para os jornalistas. 1. ed. Salvador: Calandra, 2003.

PALACIOS, Elias Machado Gonçalves e Marcos (Org.) ; GONÇALVES, E. M. (Org.) . Modelos de jornalismo digital. 1. ed. Salvador: Edições GJOL - Editora Calandra, 2003.

GONÇALVES, E. M. . La Estructura de la noticia en las redes digitales [Microforma] : un estudio de las consecuencias de las metamorfosis tecnológicas en el periodismo. Barcelona: Publicacions de la Universitat Autònoma de Barcelona, 2001.

GONÇALVES, E. M. ; PALACIOS, Marcos Silva . Manual de jornalismo na Internet noções básicas, conceitos e um guia sobre as principais publicações jornalísticas digitais no Brasil e no Exterior. Salvador: Facom-Ufba, 1997.

\section{Capítulos de Livro}

GONÇALVES, E. M. ; BORGES, Clarrissa de Jesus ; MIRANDA, Milena Nunes de . Comunicação e Informação - O Global e o Local em Austin e Salvador. In: Othon Jambeiro; Joseph Straubaahar. (Org.). Comunicação e Informação: O Local e o Global em Austin e Salvador. Salvador: EDUFBA, 2005,

GONÇALVES, E. M. ; JESUS, C. B. ; MIRANDA, M. N. . Modelos de produção de conteúdos no jornalismo digital baiano. In: Jorge Pedro Sousa. (Org.). Jornalismo de Referência. Actas do I Congresso Luso-. Porto: Edições Universidade Fernando Pessoa, 2004.

MIRANDA, Elias Machado Gonçalves Clarissa Borges M ; GONÇALVES, E. M. . Modelos de produção no jornalismo digital baiano. In: Elias Machado; Marcos Palacios. (Org.). Modelos de jornalismo digital. 1 ed. Salvador: Edições GJOl Editora Calandra, 2003.

GONÇALVES, E. M. . Changing concepts of time 50 anos depois - a contribuição de Harold Innis para o estudo do jornalismo digital. In: Denise Lavallé; Edgard Rebouças; Lícia Soares de Souza; Gaetan Tremblay. (Org.). América Terra de Utopias - Desafios da Comunicação Social. 1 ed. Salvador: Editora da UNEB, 2003.

\section{Artigos}

GONÇALVES, E. M. ; PALACIOS, Marcos . La experiencia de la enseñanza del periodismo digital en la FACOM/UFBA 1995/2005. Zer - revista de comunicación, Bilbao, Espanha, v. 20, n. 1, 2006.

GONÇALVES, E. M. ; SCHWINGEL, C. ; ROCHA, L. ; PALACIOS, Marcos . Um jornal multi-usuário, descentralizado e multimídia. O caso da Plataforma Panopticon. Pauta Geral, Florianópolis, v. 7, n. 7, 2005. 
MACHADO, Elias; PALACIOS, Marcos; SWINGEL, Carla ; ROCHA, Lenadro . Um Jornal Laboratório multimídia, multi-usuário e descentralizado. O caso da Plataforma Panopticon. Razon y palabra, Monterrey México, v. 49, 2006.

MIRANDA, Elias Machado Gonçalves Clarissa Borges M ; GONÇALVES, E. M. . Gêneros narrativos no jornalismo digital baiano. Pauta Geral, Salvador, v. Vol 5, p. 105-117, 2003.

GONÇALVES, E. M. . A Intranet como modelo de gestão no jornalismo digital. Pauta geral, Salvador, v. 6, 2004.

GONÇALVES, E. M. . O jornal como epicentro das redes de circulação de notícias. Pauta Geral, Salvador, v. Vol 4, p. 51-69, 2002.

GONÇALVES, E. M. . Os enredados no ciberespaço. Pauta Geral, Salvador, v. Vol 4, 2002.

GONÇALVES, E. M. . La circulación de la noticia en las redes digitales. Scripta Nueva, Barcelona, v. 69, n. 33, 2000.

GONÇALVES, E. M. . O novo conceito de edição no jornalismo digital. Comunicação e Sociedade, Braga, Portugal, v. 2, , 2000.

GONÇALVES, E. M. . O jornalismo digital no mercado global. Comunicação \& Sociedade, São Bernardo do Campo, v. 29, 1998.

GONÇALVES, E. M. ; PALACIOS, Marcos Silva . Três modelos de jornalismo personalizado na Internet - Fishwrap, Pointcast e CRAYON. Textos de Cultura e Comunicação, Salvador - Bahia, v. 36, 1996.

GONÇALVES, E. M. . A produção verticalizada da notícia no jornalismo digital. Pauta Geral, Salvador - Bahia, v. Vol 5, n. Ano 5, 1996.

\subsection{Publicações de Elizabeth Saad}

\section{Livros}

SAAD CORRÊA, E. Estratégias para a mídia digital, internet, informação e comunicação. 1. ed. São Paulo: Editora Senac-SP, 2003.

SAAD CORREAA, E.; KUCINSKI, B. ; LERNER, C. ; SAKAMOTO, L. M. . Em Alta - O primeiro guia on-line de jornalismo econômico. 1. ed. São Paulo: Plêiade, 1998.

\section{Capítulos de livros}

SAAD CORRÊA, E. Linguagens da informação digital: reflexões conceituais e uma proposta de sistematização. In: José Marques de Melo. (Org.). Anuário Internacional de Comunicação Lusofona 2004/Lusocom. São Paulo, Intercom, 2005.

SAAD CORRÊA, E. A era do ciberjornalista. In: Dirceu Fernandes Lopes; José Coelho Sobrinho. (Org.). A edição em jornalismo eletrônico. 1 ed. São Paulo: Edicon, 2000. 


\section{Artigos}

SAAD CORRÊA, E. O jornalismo contemporâneo no Brasil. Pauta Geral, São Paulo, v. 7, 29 nov. 2005.

SAAD CORRÊA, E. O jornalismo contemporâneo no Brasil: as mídias digitais como elo entre a crise e a busca de uma nova identidade. Razón y Palabra, México, 2005

SAAD CORREA, E. Contemporary journalism in Brazil: digital media as a link between the crisis and the search of a new identity. Brazilian Journalism Research Journalism Theory Research And Criticism, Salvador, Ba., v. 1, n. 2, 2005.

SAAD CORRÊA, E. O direito à informação e o dever de informar. Novos olhares, São Paulo, 2003.

SAAD CORRÊA, E. Arquitetura estratégica no horizonte da terra cógnita da informação digital. Revista da USP, São Paulo, v. 48, 2001.

SAAD CORREAA, E. O jornalista brasileiro na sociedade da informação: repórter da realidade, arquiteto da virtualidade. Revista Comunicações e Artes, São Paulo, v. 21, n. 34, 1999.

SAAD CORRÊA, E. Jornalismo e competitividade: o caso da Agência Estado. Revista de Comunicação, São Paulo, 1997.

\subsection{Publicações de Marcos Palacios}

\section{Livros}

PALACIOS, Marcos; GONÇALVES, Elias Machado. Manual de Jornalismo Online. 1996.

PALACIOS, Marcos; GONÇALVES, Elias Machado. Manual de Jornalismo na Internet.Salvador, UFBA, 1997.

PALACIOS, Marcos; LEMOS, André . Janelas do Ciberespaço: Comunicação e Cibercultura. Porto Alegre, Sulina, 2001.

PALACIOS, Marcos; MACHADO, Elias . Modelos de jornalismo digital. Salvador: Calhandra/Edições GJol, 2003.

\section{Capítulos de Livros}

PALACIOS, Marcos; MIELNICZUK, L. . Considerações para um estudo sobre o formato da notícia na Web: o link como elemento paratextual. In: FRANÇA, Vera; MOTTA Luiz Gonzaga; PAIVA, Raquel;WEBER, Maria Helena. (Org.). Estratégias e Cultura da Comunicação. Brasília, 2002.

PALACIOS, Marcos. Jornalismo Online, Informação e Memória: apontamentos para debate. In: Fidalgo, Antonio; Serra, Paulo. (Org.). Jornalismo Online: informação e comunicação online. Covilhã, 2003. 
PALACIOS, Marcos; MACHADO, Elias. Três modelos de Jornalismo Digital. In: Elias Machado. (Org.). O Ciberespaço como Fonte para os Jornalistas. Salvador, 2003.

PALACIOS, Marcos; MACHADO, Elias. Três modelos de Jornalismo Digital. In: Elias Machado. (Org.). O Ciberespaço como Fonte para os Jornalistas. Salvador, 2003.

PALACIOS, Marcos. Ruptura, continuidade e potencialização no jornalismo on-line: o lugar da memória. In: Elias Machado; Marcos Palacios. (Org.). Modelos de jornalismo digital. Salvador, 2003.

PALACIOS, Marcos. Jornalismo em ambiente plural? Notas para discussão da Internet enquanto suporte para a prática jornalística. In: Brasil, André; Falci, Carlos Henrique; Jesus, Eduardo de; Alzamora, Geane. (Org.). Culturas em fluxo. Novas mediações rede. Belo Horizonte, 2004.

PALACIOS, Marcos ; PAULO, Munhoz . O Uso da Fotografia no Jornalismo OnLine em Salvador e Austin: primeiros elementos de uma análise comparativa. In: Jambeiro, Othon; Straubhaar, Joseph. (Org.). Informação e Comunicação: O local e o global em Austin e Salvador. Salvador, 2004,

\section{Artigos}

MACHADO, E. ; PALACIOS, Marcos . O Jornalismo Personalizado Na Internet.Textos de Cultura e Comunicação, Salvador, n. 35, 1996.

PALACIOS, Marcos ; MIELNICZUK, L. . Considerações para um estudo sobre o formato da notícia na Web: o link como elemento paratextual. Pauta Geral, Salvador, v. 9, n. 4, 2002

PALACIOS, Marcos; MIELNICZUK, L.; BARBOSA, Suzana ; RIBAS, Beatriz ; NARITA, S. Um Mapeamento de características e tendências no jornalismo online brasileiro e português. Comunicarte, Aveiro- Portugal, v. 1, n. 2, 2002.

PALACIOS, Marcos. Fazendo Jornalismo em Redes Híbridas: Notas para discussão da Internet enquanto suporte mediático. Jornalismo Cultural, PUC/ Minas, http://www.fca.pucminas.br, 2003.

PALACIOS, Marcos; MACHADO, Elias ; SWINGEL, Carla ; ROCHA, Lenadro . Um jornal multi-usuário, descentralizado e multimídia. O caso da Plataforma Panopticon. Pauta Geral, Florianópolis, v. 7, n. 7, 2005.

PALACIOS, Marcos; MACHADO, Elias . La experiencia de la enseñanza del periodismo digital en la FACOM/UFBA 1995/2005. Zer Revista de Comunicación, Bilbao, v. 20, n. 1, 2005.

PALACIOS, Marcos. Natura non facit saltum: Promessas, alcances e limites no desenvolvimento do jornalismo on-line e da hiperficção. E Compós, Brasília, v. vol.1, n. n.2, 2005.

PALACIOS, Marcos; MACHADO, Elias ; SWINGEL, Carla ; ROCHA, Lenadro . Um Jornal Laboratório multimídia, multi-usuário e descentralizado. O caso da Plataforma Panopticon. Razon y palabra, Monterrey México, v. 49, 2006. 


\subsection{Publicações de Sebastião Squirra}

\section{Livro}

SQUIRRA, Sebastião.Jorn@lismo Online, Arte\&Ciência, São Paulo, 1998.

\section{Artigos}

SQUIRRA, Sebastião. O telejornalismo na Internet. Revista Comunicação \& Sociedade. S. Bernardo do Campo. p. 43-54, 2002.

SQUIRRA, Sebastião. Periodismo en el ciberespacio. Revista Punto Certo, Cochabamba-Bolívia, v.1, n.3, p.9-13. 1998.

SQUIRRA, Sebastião. O jornalismo do futuro. Comunicação \&Sociedade. S.B. do Campo, v.28, 1998, p.75-100.

SQUIRRA, Sebastião. Jornalismo no ciberespaço. Jornal da USP, 1998.

SQUIRRA, Sebastião. Viagem ao mundo ciberespacial. Revista Brasileira de Comunicação. Intercom. São Paulo, 1998.

SQUIRRA, Sebastião. Internet. Vale Paraibano. S.J. dos Campos, 1995.

\subsection{Publicações de Zélia Leal Adghirni}

\section{Capítulos de livros}

ADGHIRNI, Zélia L. Jornalismo online: em busca do tempo real. In: Antonio Hohlfeldt; Marialva Barbosa. (Org.). Jornalismo no século XXI : a Cidadania. Rio de Janeiro: Mercado Aberto - UFF, 2002.

ADGHIRNI, Zélia L. La presse en ligne au Bresil. In: Beatrice DAMIAN; Daniel THIERRy;Denis RUELLAN. (Org.). Paris: l'Harmattan, 2002.

ADGHIRNI, Zélia L. Jornalismo online e identidade profissional do jornalista. In: Luiz Gonzaga Motta. (Org.). Imprensa e Poder. Brasilia: Editora UnB, 2002.

\section{Artigos}

ADGHIRNI, Zélia L. La presse en ligne au Brésil: temps réel et realité - INA. Mediamorphoses, Paris, n. $n^{0}$ 4, 2002.

ADGHIRNI, Zélia L. Ribeiro, Gisleno. Informação online: jornalista ou produtor de conteúdos? Contracampo, RJ - UFF, v. 6, 2002.

ADGHIRNI, Zélia L. Jornalismo online e identidade profissional do jornalista. Comunicação e Espaço Público, UnB - Brasília, v. 1, n. nº 1, 2001. 